\title{
TOWARDS INNOVATIVE PARTICIPATION-ORIENTED PLANNING OF INFRASTRUCTURE MEASURES
}

\author{
M.-O. Löwner ${ }^{1 *}$, N. C. Bandelow ${ }^{2}$, M. Gerke ${ }^{1}$, F. Hillen ${ }^{3}$ L. Klein ${ }^{2}$, A. Schmidt ${ }^{4}$, T. Siefer ${ }^{4}$ \\ ${ }^{1}$ Institute for Geodesy and Photogrammetry, Technische Universität Braunschweig, Germany - (m-o.loewner, m.gerke)@tu-bs.de \\ ${ }^{2}$ Chair of Comparative Politics and Public Policy, Technische Universität Braunschweig (nils.bandelow, lisa.klein)@tu-bs.de \\ ${ }^{3}$ IP SYSCON GmbH, Germany - (florian.hillen@ipsyscon.de) \\ ${ }^{4}$ IVE mbH, Germany - (th.siefer@tu-bs.de@ive.de, alena.schmidt@ivembh.de)
}

\section{Commission IV, WG IV/4}

KEY WORDS: citizen participation, UAV, railway infrastructure, client-server architecture, knowledge representation

\begin{abstract}
:
Planning and realization of large infrastructure takes a lot of time due to public discussion and may be reduced by active citizen participation in an early stage of project. Insufficient or late citizen participation in large-sized projects is being held liable to effect escalation, which, again may lead to enormous delays and costs. In this contribution we propose and sketching out an internet-based planning tool, which enables the planning of large infrastructure by concerned citizens and. Therefore, it serves to objectify the debate. Within an interdisciplinary group legal issues and planning expertise will be formulized and implemented as a tool suite on a server using open source technologies. A geodatabase holds project related open and official geodata. For planning reasons, recent technology of unmanned aerial vehicle (UAV) data acquisition and feature extraction methods will be used to complement planning data. Geodata and tools will be accessed by an easy-to-use client-based mapping tool that also manages the evaluation of the users planning proposals on a server. Based on a real-life project from railway infrastructure the web-based planning tool will be valuated with real applicants.
\end{abstract}

\section{INTRODUCTION}

European society strives to carry out a turnaround in energy policy and, thus, need to carry out large infrastructural adaptions. Next to regenerative energy plants or energy and fiber optic cable networks, this also includes public transportation infrastructure like railway lines. Planning of infrastructure measures in western societies, however, does not take place in a legal vacuum but with many stakeholders participated or, at least, affected. Thus, planning, discussion with citizens, specifying ecological compensatory measures and, finally, plan approval procedures are time consuming. Take a planning permit procedure for railway lines as an example, which typically takes up to three years (Eisenbahn Bundesamt, 2020).

Active citizen participation is one key element to expedite large infrastructural projects. This is, however, mainly evaluated by negative examples like the German train station construction project "Stuttgart 21" that was positively evaluated by a feasibility report in 1994 and even went through the citizen participation process in 2010. However, since the project never found undivided acceptance the Deutsche Bahn AG decided to renew her information policy after reasonable public protest (Beteiligungsportal Baden-Württemberg, 2018).

In Germany, citizen participation is mainly covered by $\$ 3$ BauGB (germ.: building code) indicating that populace should be informed about large-scaled projects as early as possible. According to this, the general public should be enabled to join public hearings and to get insight the planning and planning alternatives. However, no statutory duty to enable active participation is called.

Belatedly citizen participation in large-sized projects, however, might trigger escalation, which, again would lead to enormous delays and costs (Geis, 2012; Klages \& Vetter, 2013; Lindloff et al., 2017b; Lisetska, 2017). Therefore, active participation in an early stage of the planning process needs to be enabled. One precondition for that is that private stakeholders are not only informed about already completed planning but also involved through active participation in an early stage. That, in turn could significantly enhance acceptance and legitimacy (Towfigh et al., 2016; Rucht, 2012).

The German Bertelsmann Foundation also emphasizes the need for citizen participation to improve and accelerate planning processes. Following that, transparency is the main key to assure citizen participation. For this, three levels are defined. This is first, a technical possibility to access data used in the planning process and, second, to be enabled to analyze it. Finally, interested and presumable concerned public should be enabled to consider the goals of the project in the broader context of political development (Bertelsmannstiftung, 2017). Internet-based technologies and modern data acquisition methods are suitable to support active citizen participation if combined with planning expertise and legislations related to the specific infrastructural project. Therefore, self-explaining tools have to enable access to official and open data as well as project related, high-precision and current (geospatial) data on the

\footnotetext{
* Corresponding author
} 
client side. In addition, mapping tools as planning interfaces have to be provided. On the server side formulized expertise has to be represented that can be used to run analysis tools to evaluate user generated planning alternatives. At large, objectification may be achieved because legal limitations and technical constraints are made transparent. In addition, concerns regarding personal dismay could also become somewhat limited. Such an approach, however, would call for an interdisciplinary consortium since, next to technical issues, considerable knowledge of legal issues and planning expertise is needed. Further, social and political sciences are required to evaluate improvements in terms of either saving time throughout the project term and citizen contentment.

In this paper, we describe the outline of the project "InnoPart" which is being funded by the German Federal Ministry of Transport and Digital Infrastructure. Its main goal is to develop a generic platform deploying a web technology and data acquisition methods next to knowledge formalization to enable active citizenship for large infrastructure projects. Next to data modelling and data acquisition by unmanned aerial vehicles (UAV), formalization of planning expertise and legal limits as well as the evaluation of the project by political scientists are included. Since the project is in a very early stage, we mainly present our concepts, which might be interesting for other similar projects as well.

In the next section, backgrounds about the necessity of participation as well as technical options are outlined. Section three explains six identified working steps for the implementation and evaluation of a GI-based participation platform followed up by a discussion concerning potential risks of the overall approach.

\section{THEORETICAL FRAMEWORK AND NECESSITY OF PARTICIPATION}

In the social sciences, direct-democratic procedures can generally increase the legitimacy and acceptance of decisions (Towfigh et al., 2016; Rucht, 2012). If this desired acceptance is linked to often strongly contested decisions regarding infrastructure projects, there is a growing need for greater opportunities of participation. Among legal scholars, the voluntariness of early public participation is critically discussed (Lindloff et al., 2017a). Therefore, it is necessary that the opportunities offered by informal participation, in addition to the planned formal participation, receive greater attention and become more widespread. From a psychological perspective, a decisive factor influencing protest behavior is the trust that is given to project stakeholders. If this trust in political and economic decision-makers is high, protests are less escalating (Thies, 2017; Bandelow \& Thies, 2014). The transparent presentation of the project plan, including the potential impact on the project, helps to build trust, while mistrust, on the other hand, contributes to long-term protest (Vogeler \& Bandelow, 2018). In order to avoid the escalation between those who are affected by large-scale projects and infrastructure measures, public participation must be planned extensively and at an early stage by the project executing agency and the included communities. The aim is a continuous, transparent cooperation, including continuous publication of all results (Geis, 2012; Klages \& Vetter, 2013; Lindloff et al., 2017b; Lisetska, 2017; BMVI, 2014. The Association of German Engineers (VDI) has published guidelines for early communication and public participation in planning and building of infrastructure projects (VDI 7000, 2015; VDI 7001, 2014). The guidelines structure the process in four phases: (1) The building of structures and competencies, (2) structured public participation, (3) support of approval procedures, (4) support of the construction phase and the project. Participation procedures must grasp the real conflicts and, in order to do so, take into account the special interest of stakeholders in the local area. A conflict, which can result from this, is the clash of two lines of conflict, the general and the local line of conflict (Fraune \& Knodt, 2017). A local line can be the NIMBY problem (not in my backyard) while more general conflicts can reach the NIABY dimension (not in anybody's backyard) (Di Nucci \& Brunnengräber, 2017). Looking at conflicts that can arise in the context of the earliest possible participation of citizens, several aspects become particularly apparent. The first structural problem is that stakeholders have the least say in those actions that are most visible to them. Regarding the organization of informal participation opportunities, this emphasizes the importance of transparent presentation of the project process and the ongoing involvement of the population, to level out differences between perception and decision making. Furthermore, if the parties involved do not develop an understanding for the views of the opposite side early on, it will become increasingly difficult to return to an objective solution to the problem. To avoid such conflicts, the equal rights of all stakeholders and a generally understandable presentation of the information available should be emphasized (BMVI, 2014; Bock et al., 2017).

Individual participation can be supported by technical solutions. However, existing standalone software packages supporting draft planning of infrastructure projects are not helpful for laymen due to complexity and prize. Since web technology primarily supports asynchronous cooperation, planning tools for large infrastructure projects can be offered in a client-server environment based on free assessable frameworks (Löwner, 2018). This supports the analysis of complex spatial problems with the help of only a web browser installed on any computer. OpenStreetMap (OSM, 2020) is the most popular volunteered mapping tool but severely restricted for planning activities, since only existing real world features ought to be mapped and published. Companies like CitizenLab (citizenlab, 2020) or Map.Social (Map.Social, 2020) offer products to support public information. However, these products seem to support the publication of project data rather than interaction with private persons. That should include the possibility to create own planning alternatives supported by formalized legal basis and planning knowledge.

Ananda et al. (2014) developed a project related but still explorative solution for citizen participation with open web frameworks. In a project called WindWolke (WindWolke, 2020), active citizenship for the planning of wind energy plants was realized. Users can virtually plan and evaluate wind power plants with the help of formulized planning knowledge implemented on the server side. However, this approach was thematically restricted and not generic.

In the context of spatial planning, the data correctness and quality are very important aspects. Orthorectified, highresolution airborne imagery and up-to-date vector data are needed to take informed decisions, both by official bodies, but also by the public. In Germany, for instance, official orthorectified imagery is only updated in a cycle of 3 years at most. The corresponding geospatial vector data layers are not necessarily updated in the same interval.

Hence, we propose to use images taken by UAV, to not only have current, but also very highly resolved visual information of the planning area. In addition, we will update vector maps using the images and derived products. Nowadays, UAV are being used for remote sensing applications (Yao et al., 2019), 
however, obstacles, for instance regarding regulations, need to be considered (Stöcker et al., 2017).

\section{SYSTEM ARCHTECTURE AND INTENDED WORKFLOW}

The broad system's architecture is depicted in Figure 1. The main part, the InnoPartAPI holds a class library containing planning tools and tools to formalise planning expertise as well as legal restrictions. This f.i. could be the definition of a minimum curve radius of rails by a given maximum speed of a train. Further, it supports the access to open or official data or, if available, high-precision data collected for the respective planning project. This API should be designed using international data exchange standards in a hierarchical way (rf. Löwner \& Becker, 2017). Framework conditions then can be chosen to build up a client that serves as a planning tool for private persons and non-experts. The user itself can evaluate the own planning alternative and finally publish it either way to feed public discussion by only applying simple actions on the client.

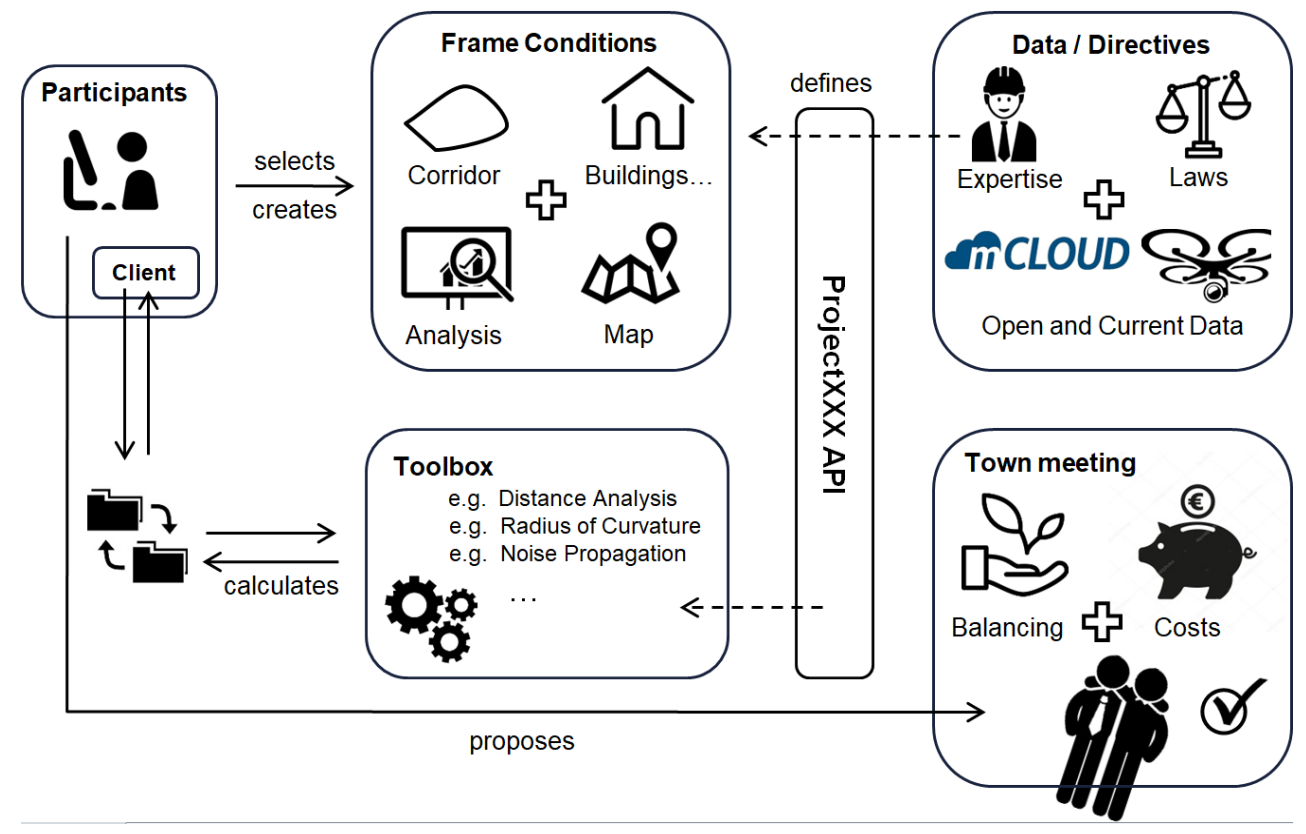

Figure 1: Architecture of the platform InnoPart for web-based citizen participation. Generic planning and formalization tools (InnoPartApi) can be used to set up a server-side planning support system that is accessed by a thin client.

The intended development workflow of the described generically and interactive citizen participation is generally divided into five parts. However, since an evaluation of the project application is desired, planning of railway infrastructure serves as a particular application:

1. Technical and applied-orientated requirement analysis along with the choice of investigation area and data basis.

2. Clarification and formalization of legal basis and planning expertise for railway infrastructure as an example for a generic application.

3. Design and implementation of a server-side API for the easy deployment of citizen participation platforms.

4. Data acquisition using UAV in the planning corridor.

5. Implementation of a running client server platform with the inclusion of current high precision data.

6. All-embracing evaluation by social scientists involving real stakeholders.

\subsection{Requirement Analysis}

The general requirements to realize a user-oriented planning support system for citizen participation for large infrastructural projects on the one hand is a self-explanatory and easy to learn client application with mapping functionality. Additionally, test parameters should be offered, which can be optionally checked by the user. Further, access to open data, official data and project related high precision data should be granted. On the other hand, server-side architecture should host or link the requested data, offer the tools needed to evaluate test parameters according to user's planning activity and should enable the storage or publishing of evaluated planning alternatives for further discussion.

Open source software seems to be the best way to implement the required project properties. This includes PostgreSQL with the spatial extension of PostGIS on the server-side. Both can be handled with Python language that itself comes with open source spatial packages. The decision on what packages are the best, however, will be taken during further project state. On the client side, open source packages like OpenLayers or Leaflet enable an easy way to implement a mapping environment while a number of JavaScript libraries may support user interaction with the server. 


\subsection{Clarification of planning expertise}

With the advantage of a highly interdisciplinary consortium, legal preconditions and planning expertise can be incorporated. Since railway infrastructure is our application, respective constraints need to be identified and formally described. Examples for that could be the minimum curve radius of rails by a given maximum speed of a train, minimum distance between railway and housing or unhallowed bisection of green areas. Many of these constrains may be formulized into simple geometrically constraints affecting just the planed route geometry. Others may also incorporate different features, since distance calculations are involved.

Some findings, however, may lead to iterative modelling action like the calculation of sound propagating and resulting distance calculations. Further, noise abatement measures may come into play. Such constraints and measures will require many features being involved when conducting the evaluation on the server.

As a result, formulized constraints and respective feature types will be stored in a database accessible by the tools implemented. Every modelled constraint, either simple or complex, will be dynamically displayed on the client side. Therefore, the chosen design of offered services is generic and monotone extendable.

\subsection{Server side modelling and implementation}

Results from the requirement analyses as well as from the clarification of expertise will be assessed to model a project data base to hold geodata as well as user information on the one side and to generically model formulized analysis descriptions for the participation platform on the other side. Latter will be queried to feed tool scrips to process and evaluate user created content, i.e. planning alternatives.

The database will hold project related geodata coming from open content or official repositories, like OSM or mCLOUD as a data basis for traffic related topics (mCloud, 2020). Also, UAV data acquired for recent project sides must be stored and referenced as well as results from feature extraction applications. Furthermore, formulized planning expertise and legal conditions have to be represented and stored to serve as input parameters for the implemented tools. Formulized knowledge in this case means at least 'type of feature' and 'geometric property' to be evaluated as well as 'parameter values' representing respective thresholds. Furthermore, associations with other feature types related to a specific test procedure have to be stored along with features that have to be created as a result of a user's planning decision. For instance, if a tunnel is proposed to be built, space for additional embankments has to be provided and therefore created as a feature at the tunnel's entrance.

Implementation will be managed using the well-known open source software packages PostgreSQL with its spatial extension PostGIS. The database implementation will be complemented with respective im- and exporter to update geodata and to provide data and analysis result, i.e. user generated planning alternatives for different stakeholders. However, fully automated integration of large geospatial data sets is not a primary target during this stage of the project.

To evaluate the user-generated planning alternatives a serverside class library (API) will be modelled using the Unified Modelling Language (UML). The hierarchical class model, therefore, forms the basis to create server-side tools for a participation platform under respect of planning expertise. Hereby, the class model of simple tools, aggregated tools and complex analysis functionality (rf. Löwner \& Becker, 2017) should be as generic as possible for reusability reasons. As a long-term objective, the establishment of a arbitrary participation platform backend is envisaged by the support of formulizing expertise and respective verification tools. Applications could be the planning of interregional streets, utility infrastructure installations or wind energy plants.

The modelling will be divided into simple helper classes and atomic tools. In general, two-dimensional and threedimensional analysis functionality will be modeled according to different geometrically constraints. This could be the geometric analysis of a curve vs. the three-dimensional calculation of soil excavations needed to fulfill the requirements of maximum slope angles for an infrastructure. The last part of the modelling and implementation will include dynamic tools, like the rough calculation of noise propagation including respective mitigation measures or shadowing effects.

Implementation will be performed with Python in combination with well-known open source programming packages like Django or shapely.

\subsection{Data Acquisition}

Improving the base data within the corridor area of interest is an important issue because it directly affects the planning process. From this point of view, a suggested solution for such improvement is to use UAV technology for capturing aerial images that should have a good image quality and cover the studied corridor area. The flexible use of these devices enables the acquisition of very high-resolution aerial images in the planning corridors within a short time. The achievable ground resolution is $5 \mathrm{~cm}$ or better. In this project, these images play an important role on several levels. On the one hand, they help the participants to connect the geodata provided by different (public) authorities with reality more easily: for example, the boundary of a nature reserve can be visualized directly in aerial images and especially for laymen such partly virtual boundaries are then much easier to grasp. Furthermore, the images can be used to standardize or improve the geometric information from other, i.e. open sources. In addition to the visual information from the color image, the participants receive valuable basic data for planning purposes through a very detailed elevation model of the corridor.

Finally, participating citizens are given the opportunity to contribute their local knowledge about the objects in their cultural landscape. Location-based information can be created and published in the web platform. This can be, for example, geo-information that designates objects worthy of protection and related to the (cultural) history of the location.

In this project all steps for the acquisition, processing and integration of UAV-based data into the approach are covered. Especially the acquisition of corridors poses some challenges, which have to be investigated and solved for this project. In contrast to flying over individual, spatially clearly defined areas, corridors involve flying over areas of different use and ownership as well as traffic routes. This means that many different parties have to be involved in the application for a flight permit. In order to make these steps efficient, it will be necessary to communicate with all parties involved at a very early stage (land holders, public administrations, possibly Deutsche Bahn). This aspect should be considered at a very early stage, including meetings with the advisory board and affected citizens.

From a technical point of view, corridor flights also represent a special case: the flight segments must be selected in such a way 
that legal requirements for the flight in the line of sight can be met. Furthermore, it is necessary to geometrically register and signal ground control points. It is necessary to examine how much effort is required with regard to the number and distribution of the control points. There are many publications in which this aspect is investigated (c.f. Gerke and Przybilla, 2016), but a specific, scientifically supported investigation of corridor flights is not yet available.

The data generated in the photogrammetric evaluation (digital surface and terrain models, orthomosaic corridor, and 3D point clouds) are used as a basis for the correction and enrichment of the underlying geodata. In this context, methods for semiautomatic classification and mapping of objects such as streets, houses, vegetation areas are also investigated (c.f. Crommelinck et al., 2016).

\subsection{Client side modelling and implementation}

The web client enables the user to access the relevant data in an appropriate form. Furthermore, it will provide interaction functionalities, e.g. to sketch own planning alternatives and compare planning parameters. All calculations are conducted on the server, so that the client communicates with the server via established interfaces like REST or WebSockets.

Open JavaScript / TypeScript frameworks like Angular or ReactJS will be used as the technological basis for the web client. However, it is necessary to extend the technological stack with various libraries for different aspects of visualization or interaction. For example, it has not yet been determined whether to use Leaflet or OpenLayers as the main mapping framework for example. This ongoing discussion is related to a detailed application definition within the consortium.

Geodata is planned to share among consortium members and software parts based on international standards defined by the Open Geospatial Consortium (OGC) like Web Map Service (WMS) and Web Feature Service (WFS).

As the web client is designed to be used by nonprofessionals in the first place, a focus on user interaction is essential. Thus, the interface has to be self-explanatory and easy to use. To increase the user experience, appropriate wizards as well as an assisted and guided user approach are an important key during the design and development process.

\subsection{Evaluation}

In order to test the usability of the public participation platform, it also needs to be evaluated for functionality and acceptance and, if necessary, technically upgraded. Students are initially planned as test persons for the evaluation. The work of the test persons will be carried out in terms of acceptance of the technical solution and general planning. First objections regarding usability, presentation and data basis are documented in this way. The evaluation is carried out using established social science methods, such as participant observation, standardized surveys and qualitative expert discussions. Based on this, criteria and impact models are developed to estimate the success of the tool with regard to the defined objectives. From studies designed specifically for the participation of the citizens, fourteen different criteria for the evaluation of regional participation can be established (Vatter, 1996). More recent literature expands these with sub-criteria and classifies them into criteria of participation, criteria of process, and criteria aimed at both participation and process (Alpiger, 2019). The criteria of participation include, for example, institutional integration, representation of the individual participants, and reliability of expectations. The criteria of the process include, for example, fairness, early and interactive participation, the joint definition of decision-making and procedural rules, and the expertise of the participants. The transparency of the process and direct and comprehensible information are part of both participation and process criteria. To successfully evaluate the benefits of the planning tool, a real infrastructure planning project is accompanied by the project. Because the Project InnoPart (rf. Fig. 1) and the developed system are used as "Platform-as-a-Service" (PaaS) technology, the previously developed approaches must be evaluated with regard to their technical transferability for different application scenarios. In addition, it is to be examined how "Software-as-a-Service" (Saas) offers for recurring use cases can be derived from the PaaS environment. This also includes the definition of use cases outside the one defined in the project. The need identified here has then to be compared with the possibilities of the generic InnoPartAPI, which may result in requirements for follow-up projects or economic exploitation options.

In addition to the evaluation of what has been achieved during the project period, the economic use must also be considered. It will be evaluated to what extent the targeted usage options can be realized or expanded with the existing system.

\section{DISCUSSION}

We propose a client-server architecture to support early citizen participation in large infrastructure projects. Client-based mapping tools enable concerned citizens to propose for alternative planning solutions. On the server-side, formulized legal issues and planning expertise along with implemented software tools manage to evaluate the proposed alternatives. In Addition to open and official geodata, planning will be supported by the provision of current high precision data from UAVs. It is anticipated that objectification in the planning process leads to a higher overall acceptance and, therefore, to a reduced period of the project.

Risks that must be considered when implementing a tool for participation are gaps in effectiveness. It should be noted, however, that decisions and compromises that arise in the course of planning with the involvement of citizens may be overturned in the course of the process or, in the course of different procedures, may no longer be accepted by those involved as before. Nevertheless, this risk can be offset by keeping stakeholders informed and continuously involving them. Another aspect that will be considered before implementing the tool, is the "perfect time" for its use. It should be noted that participation rarely occurs too early and often too late. However, the challenge of involving stakeholders early is that it is not possible to provide information on all open questions regarding the plan and that transparency is provided, but in line with a possible lack of clarity (Albrecht, Grüttner, Lenk et al. 2013). Nevertheless, the implementation of the tool and the associated participation must take place early enough so that those who are affected still have a wide scope for decisionmaking and co-determination. Besides the general risks, it has not yet been demonstrated that technical constraints and complex legal situation can be formulized in a way that supports automatic evaluation of planning alternatives. That also has implications on the realization of a user friendly and easy to handle web client. Acceptance of this user interface is, therefore, part of the evaluation process.

Concerning the data acquisition, the systematic capture of UAV images in corridors will be examined. Besides, the automated update of geospatial (vector) data contributes to the state-of-theart. 


\section{ACKNOWLEDGEMENTS}

The project InnoPart (project number 19F2086) is funded by the Federal Ministry of Transport and Digital Infrastructure (BMVI) within the research initiative mFUND.

\section{REFERENCES}

Albrecht, R., Grüttner, A., Lenk, T., Lück, O., Rottman, O., 2013. Optionen moderner Bürgerbeteiligung bei Infrastrukturprojekten. Ableitungen für eine verbesserte Beteiligung auf Basis von Erfahrungen und Einstellungen von Bürgern, Kommunen und Unternehmen. Berlin: BMG AG.

Alpinger, C., 2019. Partizipative Entsorgungspolitik in der Schweiz. Evaluation von Beteiligungsverfahren bei der Suche nach Lagerstätten für radioaktive Abfälle. Baden-Baden: Nomos.

Ananda, F.T., Ngigi, M.M., Kuria, D.N., 2014. Web-based GIS Approach to Enhance Public Participation in Development Planning: Developing The Emuhaya Constituency WebGIS Portal. European International Journal of Science and Technology 3(9), 103-114.

Bandelow, N.C., Thies, B., 2014. Gerechtigkeitsempfindungen bei Großprojekten als Ursache von Konflikteskalationen? Vertrauen und Legitimität als moderierende Faktoren illustriert am Beispiel der Konflikte um die Erweiterung des Frankfurter Flughafens. Politische Psychologie 4, 24-37.

Bertelsmannstiftung, 2017. Transparenz bei Bürgerbeteiligung - Handreichung für Projektverantwortliche (Allianz Vielfältige Demokratie). https://www.bertelsmannstiftung.de/fileadmin/files/Projekte/Vielfaeltige_Demokratie_ge stalten/Transparenz_bei_Buergerbeteiligung.pdf.

Beteiligungsportal Baden-Württemberg, 2018: Filder-Dialog zu Stuttgart 21, https://beteiligungsportal.badenwuerttemberg.de/de/informieren/beteiligungsprojekte-derlandesregierung/lp-15/dokumentation-filder-dialog-s21/. (Accessed 26 January, 2020)

Bock, S., Reimann, B., Abt, J., Lettow, M., Vorwerk, U. (2017): Beteiligungsvorhaben bei umweltrelevanten Vorhaben Abschlussbericht. In: Für Mensch \& Umwelt 37: 83-101.

Bundesministerium für Verkehr und digitale Infrastruktur, 2014: Handbuch für eine gute Bürgerbeteiligung. Planung von Großvorhaben im Verkehrssektor. Berlin

citizenlab, 2020. Bürgerbeteiligung vereinfacht und vermittelt. https://www.citizenlab.co/de. (Accessed 26 January 2020)

Crommelinck, S., Bennett, R.M., Gerke, M., Nex, F.C., Yang, M.Y, Vosselman G., 2016. Review of automatic feature extraction from high-resolution optical sensor data for UAVbased cadastral mapping. Remote Sensing 8(8), 689.

Di Nucci, M.R., Brunnengräber, A., 2017. In Whose Backyard? The Wicked Problem of Siting Nuclear Waste Repositories. European Policy Analysis 3(2), 295-323.
Eisenbahn Bundesamt, 2020. Planfeststellung, https://www.eba.bund.de/DE/Themen/Planfeststellung/planfests tellung_node.html. (Accessed 26 January 2020)

Fraune, C., Knodt, M., 2017. Challenges of Citizen Participation in Infrastructure Policy-Making in Multi-Level Systems - The Case of Onshore Wind Energy Expansion in Germany. European Pocily Analysis 3(2), 256-273.

Geis, A., 2012. Das „Schlichtungsverfahren“ zu „Stuttgart 21“. Die neueste demokratische Errungenschaft? In: Asbach O., Schäfer R., Selk V., Weiß A. (eds), Zur kritischen Theorie der politischen Gesellschaft. VS Verlag für Sozialwissenschaften, Wiesbaden, 143-163.

Gerke, M., Przybilla, H.-J, 2016. Accuracy of RTK-GNSSsupported UAV image blocks. Photogrammetrie Fernerkundung Geoinformation (PFG) 2016 (1), 17-30.

Klages, H., Vetter, A., 2013, Bürgerbeteiligung auf kommunaler Ebene. Perspektiven für eine systematische und verstetigte Gestaltung. Berlin: Edition Sigma, 3-69.

Lindloff, K., Lisetska, K., Eisenmann, T., Bandelow, N.C., 2017a.: Regionale Betroffenheit in informellen Beteiligungsverfahren bei Infrastrukturprojekten. der moderne staat $1,89-115$.

Lindloff, K., Lisetska, K., Stender-Vorwachs, J., 2017b: Frühe Öffentlichkeitsbeteiligung bei der Planung von Schieneninfrastruktur. Eisenbahntechnische Rundschau, 1+2, 42-47.

Lisetska, K., 2017. Effizienzsteigerung in der Planung von Infrastrukturprojekten durch Bürgerbeteiligung. Hamburg, PMC Media

Löwner, M.-O., 2018. Web-basierte Planungstools als Bürgerbeteiligungsplattform für erneuerbare Energien. In: Bill, R., Zehner, M. L., Lerche, T., Schröder, J. (Eds.), GeoForum MV 2018 - Geoinformation und Digitalisierung, pp. 95-103.

Löwner, M.-O., Becker, T., 2017. Framework for on an Open 3D Urban Analysis. In: A. Abdul-Rahman (ed.), Advances in 3D Geoinformation, Lecture Notes in Geoinformation and Cartography, DOI 10.1007/978-3-319-25691-7_17, 2017, 305321.

mCloud, 2020. Öffentliche Daten in Bewegung. https://www.mcloud.de/ (Accessed 26 January 2020).

Map.Social, 2020. map-based engagement platform. https://map.social/. (Accessed 26 January 2020)

OSM, 2020. OpenStreetMap - Deutschland, https://www.openstreetmap.de/. (Accessed 26 January 2020)

Rucht, D., 2012. Bürgerbeteiligung in Deutschland: Erfahrungen und Herausforderungen am Beispiel von Stuttgart 21. In Friedrich-Ebert-Stiftung (Hrsg.), Vertrauen durch mehr Beteiligung - Vertrauen in Europa (S. 8-15). Berlin: FriedrichEbert-Stiftung

Stöcker, C., Bennett, R., Nex, F., Gerke, M., Zevenbergen, J. 2017. Review of the Current State of UAV Regulations. Remote Sens. 2017 (9), 459. 
Thies, B., 2017. Vertrauen und Protestbereitschaft: Erkenntnisse aktueller Eskalationsforschung. Wertermittlungsforum 34, 157-160.

Towfigh, E. V., Goerg, S. J., Glöckner, A., Leifeld, P., Llorente-Saguer, A., Bade, S., Kurschilgen, C., 2016. Do directdemocratic procedures lead to higher acceptance than political representation? Public Choice, 167, 47-65.

Vatter, A., 1996. Evaluationskriterien für Mitwirkungsverfahren. In: Rehmann-Sutter, C., Klein, A., Seiler, H., Vatter, A. (Eds.), Demokratische Risikopolitik. Vorschlag für ein Mediationsverfahren in Kanton Basel-Landschaft, Liestal: Verlag des Kantons Basel-Landschaft, pp. 111-122.

VDI 7000, 2015. VDI-Richtlinie 7000: Frühe Öffentlichkeitsbeteiligung bei Industrie- und Infrastrukturprojekten, Berlin: Beuth Verlag.

VDI 7001, 2014. VDI-Richtlinie 7001: Kommunikation und Öffentlichkeitsbeteiligung bei Planung und Bau von Infrastrukturprojekten, Berlin: Beuth Verlag.

Vogeler, C. S. \& Bandelow, N. C. (2018): Mutual and Self Perceptions of Opposing Advocacy Coalitions - Devil Shift and Angel Shift in a German Policy Subsystem. Review of Policy Research 35(5), 717-732.

WindWolke, 2020. WindWolke: Internetbasierte High-Tech Lösung zur Planung von Windenergieanlagen durch Projektierer, Kommunen und Privatpersonen. https://www.tubraunschweig.de/igp/projekte/abgeschlossene-

projekte/windwolke. (Accessed 26 January 2020)

Yao, H., Qin, R., Chen, X., 2019. Unmanned Aerial Vehicle for Remote Sensing Applications - A Review. Remote Sens. 2019 (11), 1443.

Chan, K.L., Qin K., 2017: Biomass burning related pollution and their contributions to the local air quality in Hong Kong. Int. Arch. Photogramm. Remote Sens. Spatial Inf. Sci., XLII2/W7, 29-36. doi.org/10.5194/isprs-archives-XLII-2-W7-292017.

Dubayah, R.O., Swatantran, A., Huang, W., Duncanson, L., Tang, H.,Johnson, K., Dunne, J.O., Hurtt, G.C., 2017. CMS: LiDAR-derived Biomass, Canopy Height and Cover, Sonoma County, California, 2013. ORNL DAAC, Oak Ridge, Tennessee, USA. doi.org/10.3334/ORNLDAAC/1523.

Förstner, W., Wrobel, B., 2016: Photogrammetric Computer Vision. Springer Nature, Cham.

Gago-Silva, A., 2016. GRASS GIS in Grid Environment. doi.org/10.6084/m9.figshare.3188950.

GRASS Development Team, 2015. Geographic Resources Analysis Support System (GRASS) Software, Version 6.4. Open Source Geospatial Foundation. grass.osgeo.org (1 June 2017).

GRASS Development Team, 2017. Geographic Resources Analysis Support System (GRASS) Software. Open Source Geospatial Foundation. grass.osgeo.org (20 September 2017).
Lennert, M., GRASS Development Team, 2017. Addon i.segment.stats. Geographic Resources Analysis Support System (GRASS) Software, Version 7.2, Open Source Geospatial Foundation. grass.osgeo.org/grass7/manuals/addons/i.segm ent.stats (1 June 2017).

Maas, A., Rottensteiner, F., Heipke, C., 2017. Classification under label noise using outdated maps. ISPRS Ann. Photogramm. Remote Sens. Spatial Inf. Sci., IV-1/W1, 215-222. doi.org/10.5194/isprs-annals-IV-1-W1-215-2017.

Michalis, P., Dowman, I., 2008: A Generic Model for AlongTrack Stereo Sensors Using Rigorous Orbit Mechanics. Photogrammetric Engineering and Remote Sensing 74(3), 303309.

Smith, J., 1987a. Close range photogrammetry for analyzing distressed trees. Photogrammetria, 42(1), 47-56.

Smith, J., 1987b. Economic printing of color orthophotos. Report KRL-01234, Kennedy Research Laboratories, Arlington, VA, USA.

Smith, J., 2000. Remote sensing to predict volcano outbursts. Int. Arch. Photogramm. Remote Sens. Spatial Inf. Sci., XXVIIB1, 456-469.

Revised January 2020 